\title{
KSA-Self Assessment of Pain Management Medication Safety for Hospitals
}

\author{
Yousef Ahmed Alomi ${ }^{* *}$, Eman Kamal Ibrahim² \\ ${ }^{I}$ The Past General Manager of General Administration of Pharmaceutical Care and Head, National Clinical \\ pharmacy, and pharmacy practice and Pharmacy $R \& D$ Administration, Ministry of Health, Riyadh 11392, Riyadh, \\ SAUDI ARABIA \\ ${ }^{2}$ Senior Quality Specialist/Pharmacist, Total Quality Management Administration, King Saud Medical City, Riyadh, \\ SAUDI ARABIA
}

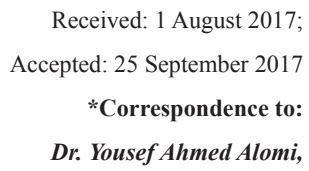

The Past General Manager of General Administration of Pharmaceutical Care, Head, Saudi Clinical Pharmacy Forum, and Pharmacy R \& D Administration, Ministry of Health, Riyadh 11392, Kingdom of Saudi Arabia (KSA) Email Id:yalomi@gmail.com

Copyright: (C) the author(s),publisher and licensee Indian Academy of Pharmacists. This is an openaccess article distributed under the terms of the Creative Commons Attribution Non-Commercial License, which permits unrestricted non-commercial use, distribution, and reproduction in any medium, provided the original work is properly cited.

\begin{abstract}
Pain management program is essential and required the program to prevent the adverse event, drug misadventure, and pain killer medications related death at health care institutions. One of the tools to evaluate the performance and drug safety of the pain management program. It is the assessment of ten directions of medication safety including patient information, medication information, communication process of medicines, drug packaging and labeling, drug devices, work environment and staffing management, competency and education, patient or family education, and quality and risk management. The new tools as self-assessment of pain management medication safety and modified of former the United States of America and Canada Institution Safe Medication Practice (ISMP) ten elements with additional to the health care institution demographic information and according to the pharmacy law and regulations in Saudi Arabia. This new method can assess the hospital's pain management implementation and detect the gap problems implementation, risk of the patient safety level of pain management. The tool had a scoring scale system of acceptable or risk level or need improvement with the annual application. The tool is first self-assessment tool of pain management medication in Saudi Arabia. The tool is highly recommended to apply at all government and private hospitals in Kingdom of Saudi Arabia.

Key words: Pain Management, Safety, Medications, Self-Assessment, Ministry of Health, Saudi Arabia.
\end{abstract}

\section{INTRODUCTION}

Managing the patient's pain is one of the patients right. Therefore, the healthcare facility should do the best to satisfy the patient, that's by relieving his pain with using the different approach despite the pain score variety with each patient. As a result, many of incidents occurred of medication error events or adverse reaction or even fatal occurrence that's conclusion of the safety of pain management medication not compromised. ${ }^{[1-7]}$ Problems with pain management can link to absent of complete a structural pain management program with inadequate close patient monitoring. ${ }^{[8-13]}$ There is a wide variety of different analgesics available on the market; dosage forms that range from lollipops to patches; the differences of delivery vehicles from implantable devices to patient-controlled analgesia (PCA), 
and different routes of administration. It is imperative for hospitals to revise this issue to ensure a safe, efficient, and realistic approach to managing pain. There are minimum preventive strategies to ensure the safety of pain management medication. One of the strategies used is a hospital self-assessment tool to improve pain killer medications safety at all hospital units; including all aspects and process of patient safety. The authors are not familiar with any published studies locally around, or the Middle East countries or even in the world wide discussed self-assessment of pain management medications safety.

\section{Current Practice of Pain Management Medications}

The power of mandatory requirement as law and regulation, only the medication listed as narcotic and controlled counted for that purpose. The goal is to ensure the adherence with the legal and authorized body requirements. The patient safety not considered, and the picture is not completed and will not clear by the only simple count of those medications against full legal prescriptions. The authors' dimension of the image as measuring the processes of handling that group of medicines, the safety practice and monitoring the effectiveness not considered. Now a day the patient safety reviewed, and many hospitals developed policy, defining high-risk medications and implemented many preventive measures as the tall man letter, labeling, developing guideline etc. Nobody focused on medication safety rather than the mandatory requirement and general solutions by patient safety initiatives. The authors suggest developing the unique tool for pain management medications, which can use by any hospital with preferable of accredited hospital where many systems and process related to quality and patient safety in place. The suggested tool will help any hospital to assess the medication safety practices in their units and compare it with other hospital surrounding the use of pain management drugs, identify the gap and creating many opportunities for improvement, and compare the hospital experience with the aggregated experience of others. The suggested tool contains standards that address the use of pain management medications in the facility. ${ }^{[14]}$

\section{Why Suggested Tool?}

The suggested tool developed to open the eye to new preventive measures that are in place in many hospitals and may need to implement at others to support the medication safety. Many of the standards included in the suggested tool already required by national and international accreditation standards or Institution of Safe Medication Practice (ISMP) Medication Safety Self-Assessment $\AA$ for
Hospitals standards that represent the primary function in the United States of America (USA). ${ }^{[15-18]}$ The system or process improvement supports the handling of pain management medications. Some of those standards or standards are new to many hospitals; implementation of those will lead to raising the clinical practice level and may help in reaching best practice and improve the safety of pain management medications by preventing or minimizing harms that may result from misuse.

\section{Method of designing Tools}

The tools conceived in a manner that first processes of handling medications have listed and detail required is in shape of standards. All the standards related to the safe use of pain management medications. Standards create a baseline of activities that will play a role in preventing/ minimize the risk, enhancing medication safety with pain management medications, and assess these activities continuously. The self-assessment consisted of two parts. Part one about demographic information section that includes information about the type of hospital, hospital bed number, the type of service hospital provides the presence of pharmacy practice services, number the location of pharmacy, number of pharmacists, number of clinical pharmacists. The second part of the advanced tool consisted of ten chapters that significantly influence the safe use of pain management drugs. Each chapter defined by one or more focus area of a safe medication system. Each focus area contained the standards. The total numbers of the standards were one hundred and twenty six. All standards have equal weight. Self-assessment standards for pain management medicationprovided to help the healthcare providers to evaluate the success of achieving each Focus area as explored in appendix 1 and appendix 2 .

\section{DISCUSSION \& RESULT}

How to use the Pain Management Medications SelfAssessment tool?

There are many practitioners perform of such medication assessment with different responsibilities from various units/departments. So formulating a multidisciplinary team for that purpose strongly recommended. The team should develop representing all core function and system to be able to assess all processes. The team should train and empowered with needed information. Before that, the team must have to charge with the responsibility to evaluate in anywhere and anytime the pain management medications used. The team has to do a comprehensive action plan; responsibilities should distribute among team 


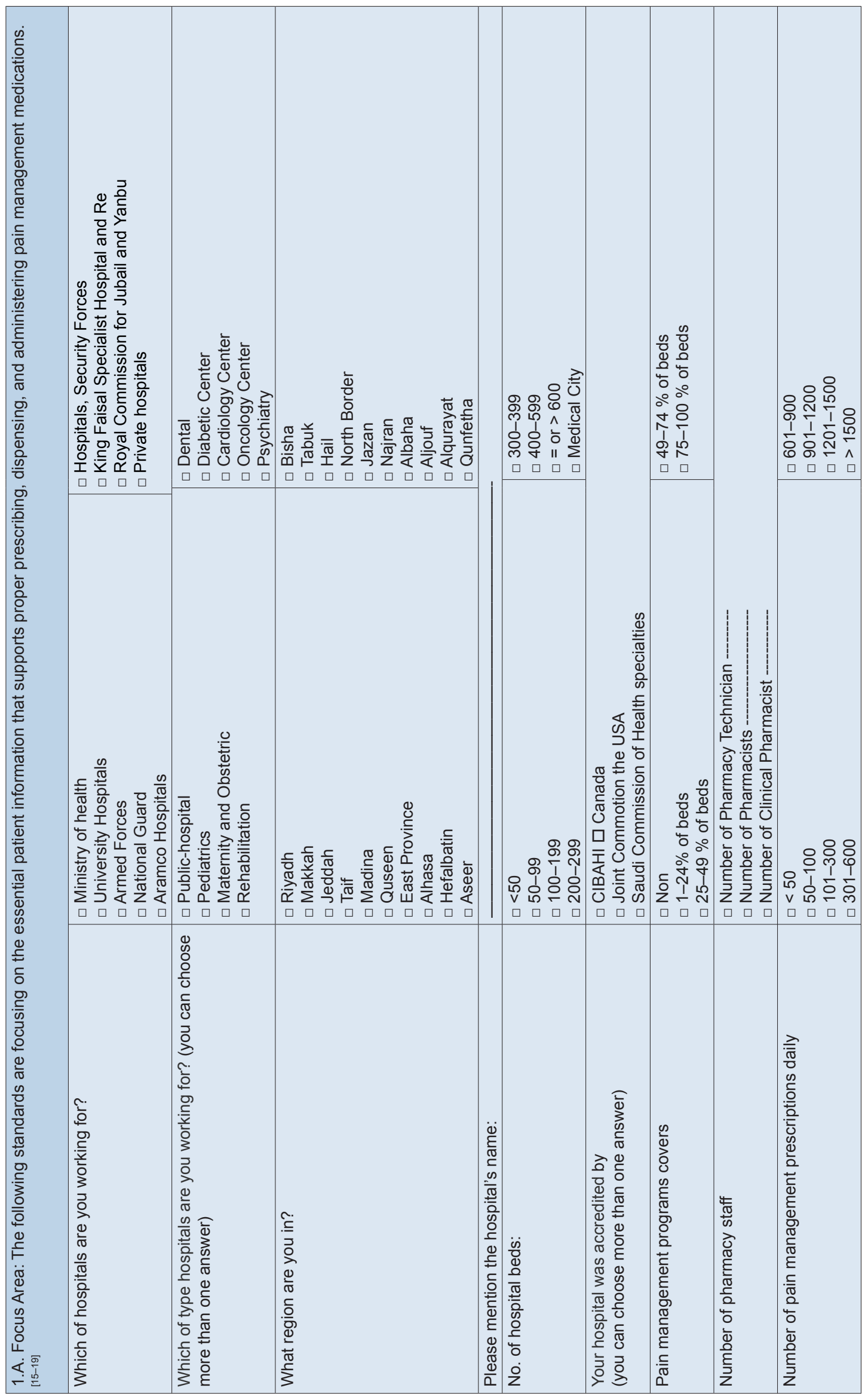




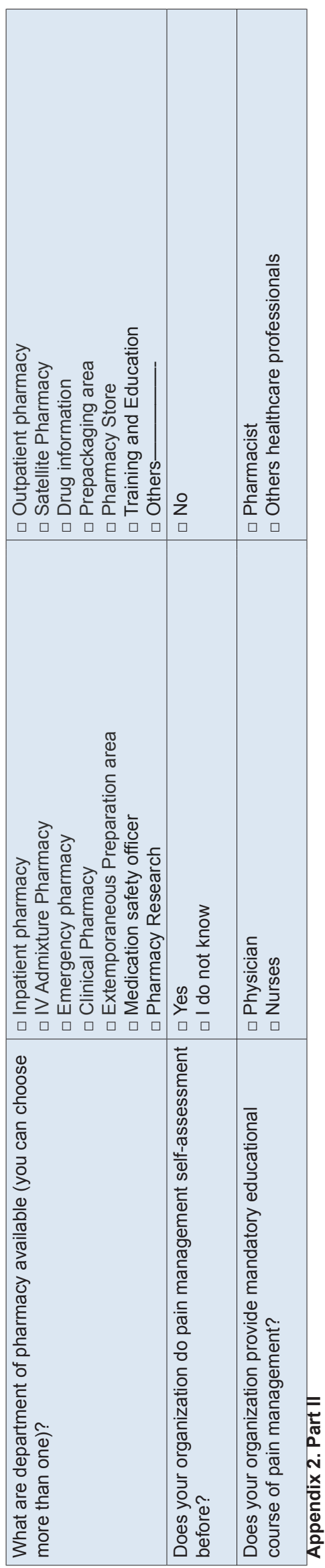

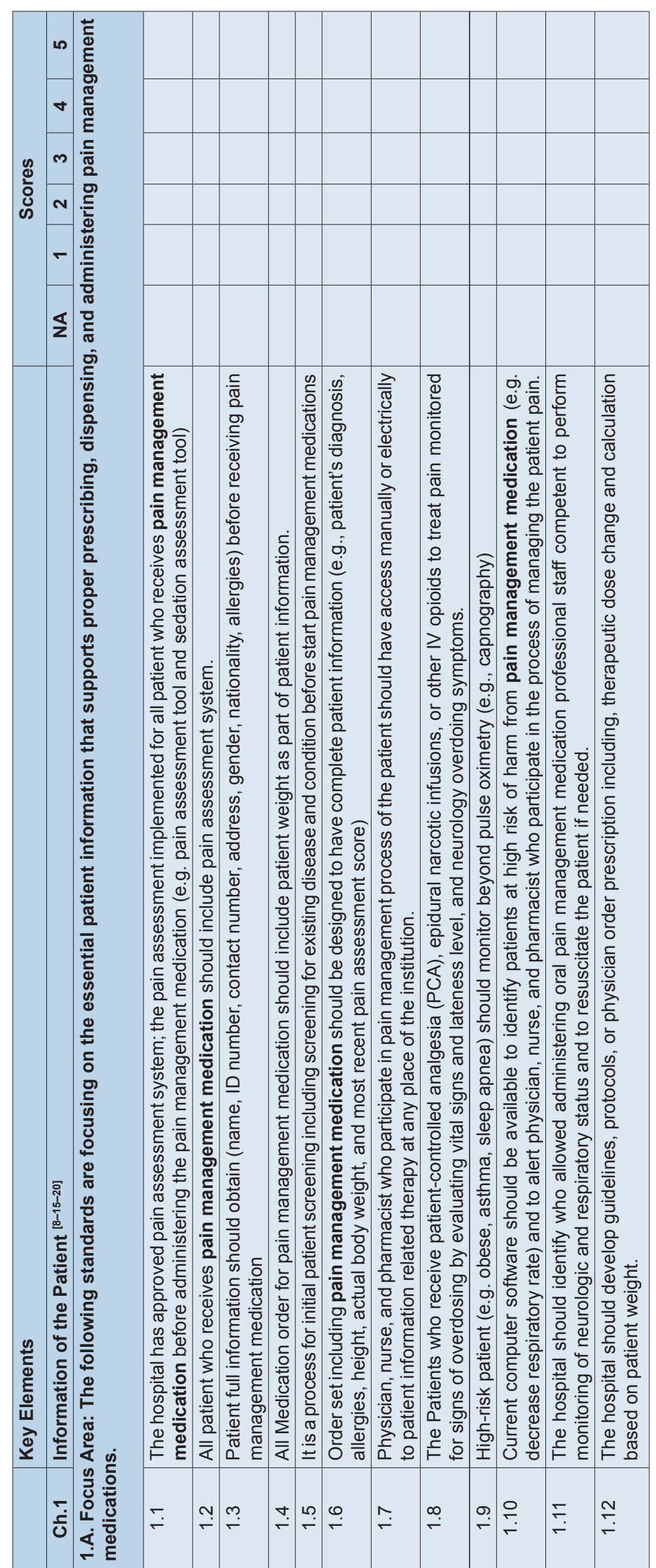




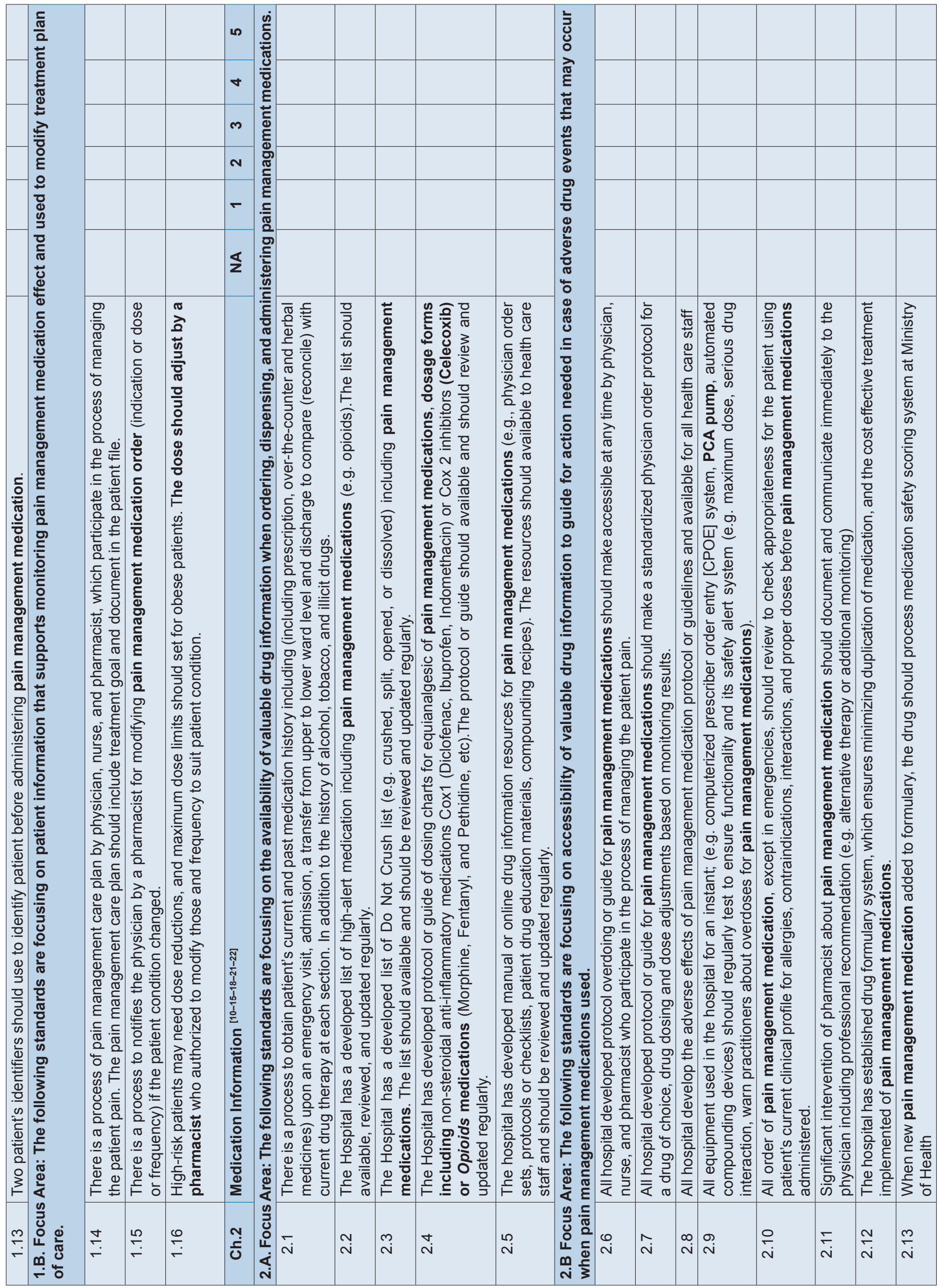




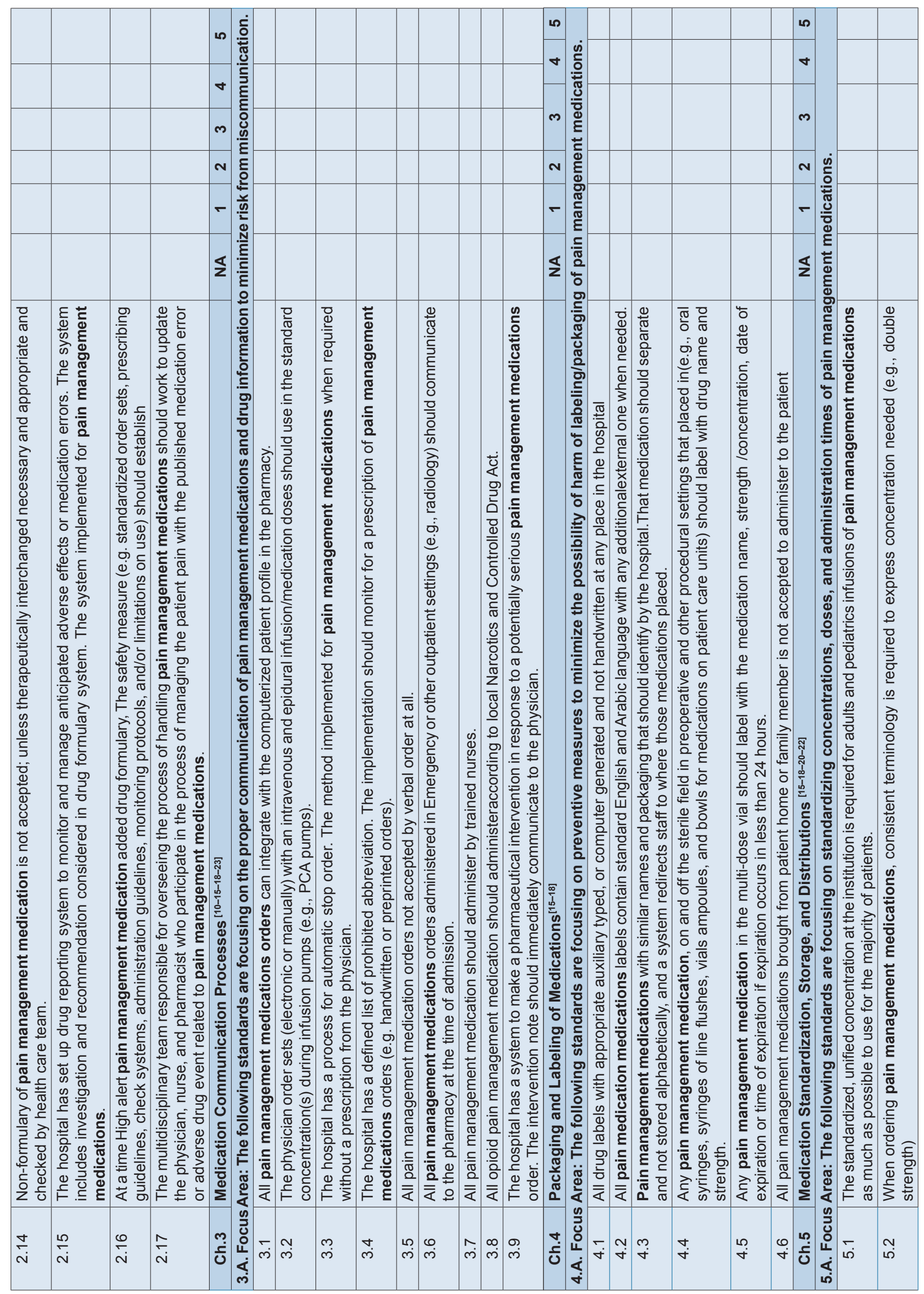




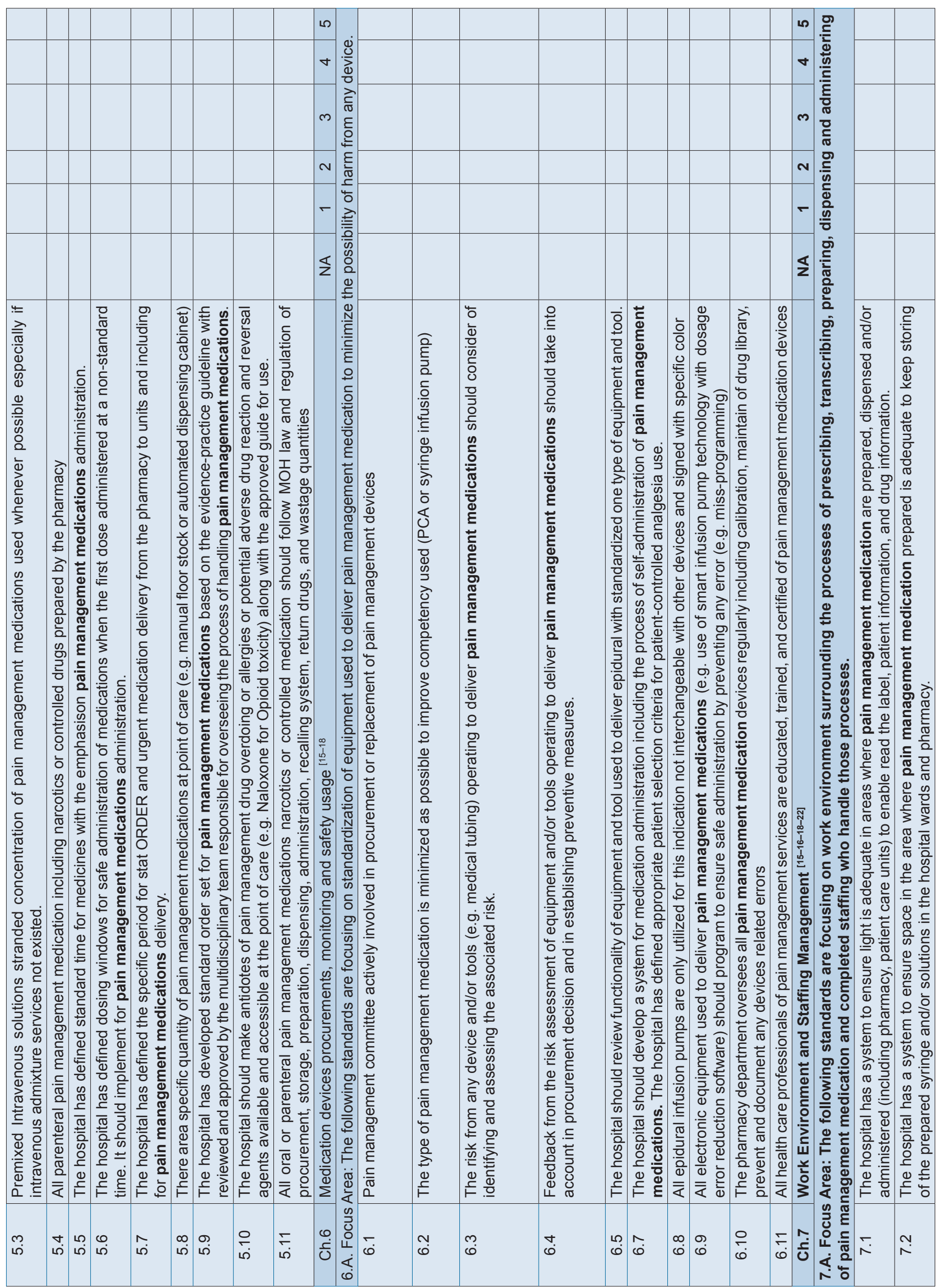




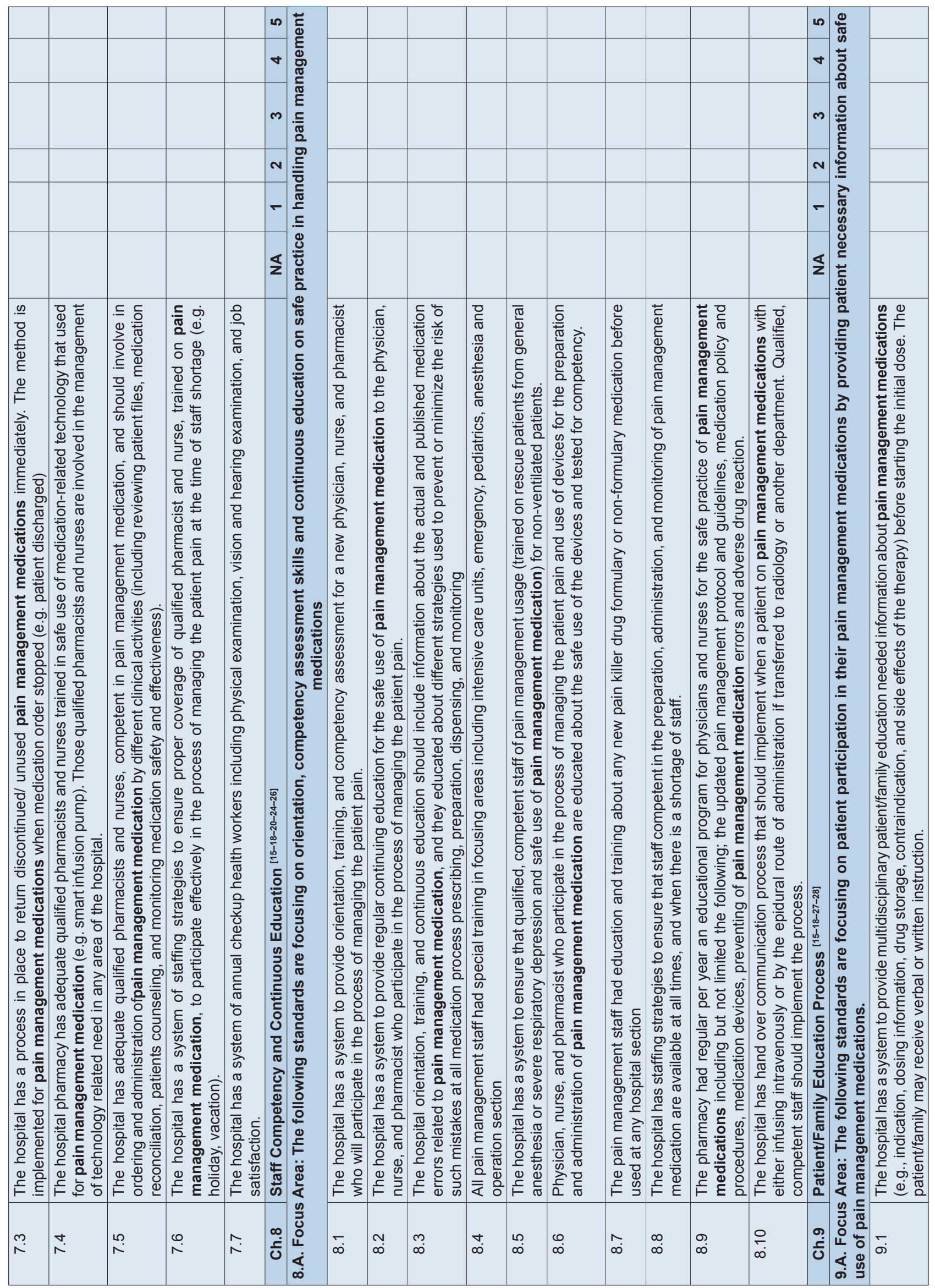




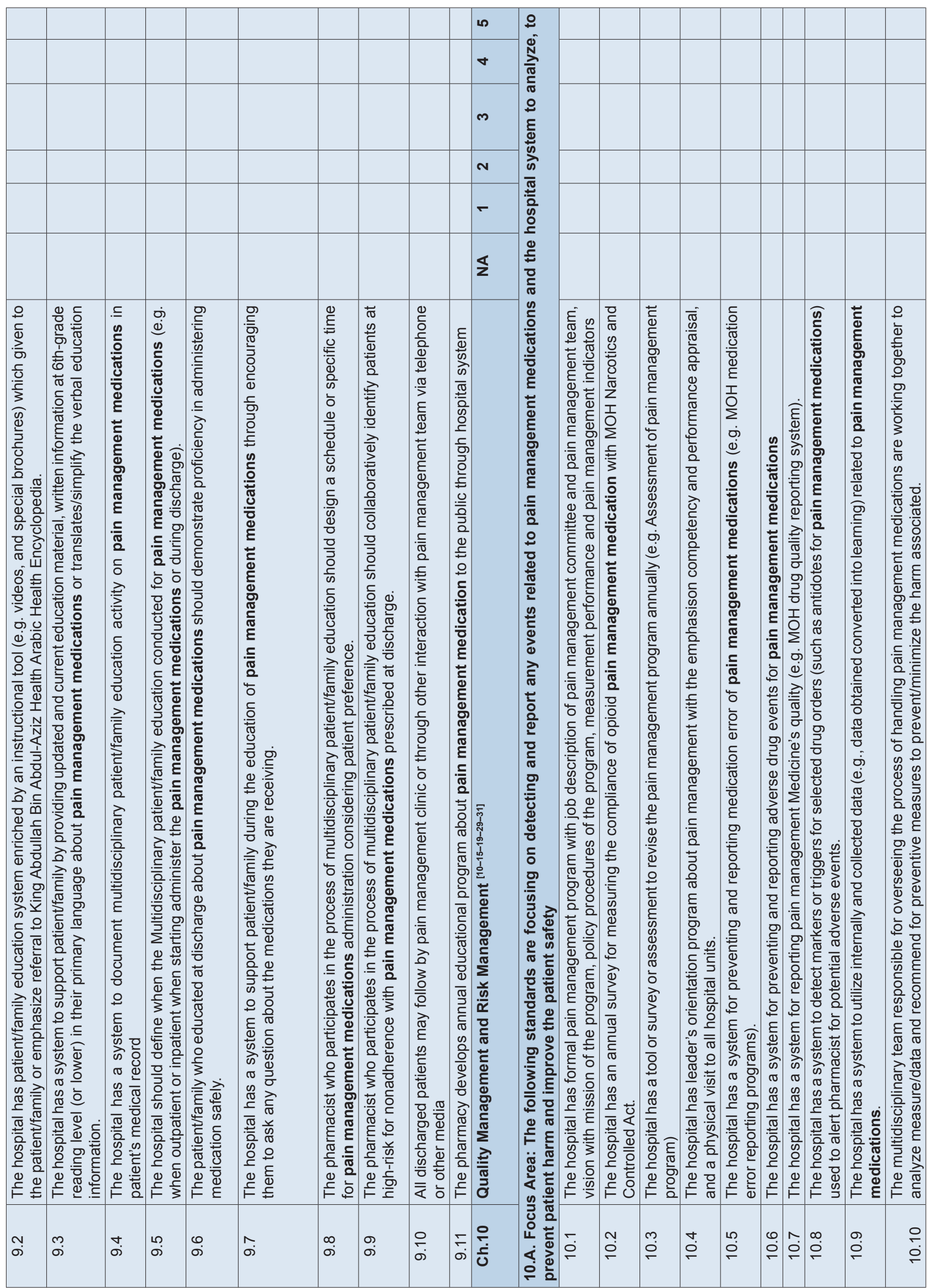




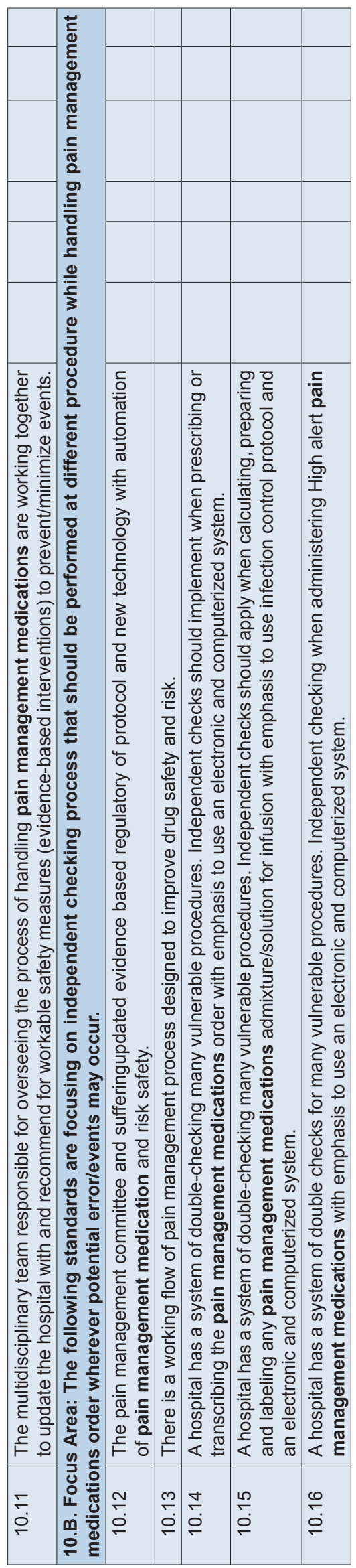

members; the timeframe should determine, and followup should conduct. The team could be the members of medication safety committee, pain management committee, or may consist ofaphysician, nurse, pharmacist, quality management person, and patient safety representative.

Each self-assessment standards evaluate hospital services by using the Likert scale for scoring from 1-5 with place a checkmark in the appropriate column scoring key as following: (1) There has been no activity to implement this standard, (2) This standard has been formally discussed and considered, but it has not implemented. (3) This specification has partially carried out in the hospital for some or all areas, patients, drugs, and staff, (4) The standard is fully implemented in the hospital for some areas, patients, drugs, and staff. (5) The measure fully implemented throughout the hospital for all patients, drugs, and staff. Moreover, it may choose NOT APPLICABLE if care not provided. The data from the assessment should aggregate and submitted to the authorized body. The information about the gap and opportunities for improvement has to share with the Leadership to make the valuable recommendation to support medication safety of pain management drugs. Finally, the Safety level of the Hospital in handling Pain Management Medication should determine as following: "Accepted level" of safety in pain management medications; if the final score is $473-630(75 \%-100 \%)$. "At risk level" of safetyin pain management medications if the final score between 378-472 (60\%-74\%) "Need Improvement level" safety in pain management medications if the final score is less than $378(60 \%)$.

\section{CONCLUSION}

The authors strongly recommend using the suggested tool. That may need to apply the recommended tool at many hospitals by the hand of the qualified team, which may need to have a sponsored body national or international body to help in support. Later on, this tool has to use in each facility has pain management medication especially narcotic and controlled medications, and it is a mandated to implement to reach the minimum accepted level of patient safety.

\section{ACKNOWLEDGEMENT}

I want to thank all pain management committees and team members at all hospitals for their cooperation to 
implement the program.

\section{CONFLICT OF INTEREST}

None

\section{ABBREVIATION USED}

KSA: Kingdom of Saudi Arabia, PCA: patientcontrolled analgesia, MOH: Ministry of Health, USA: United States of America, ISMP: Institution Safe Medication Practice.

\section{REFERENCES}

1. Al-Rowaili A, Al-aqeel SA, Al-Naim LS, Al-Diab Al. Appropriateness of cancer pain management in Saudi teaching hospital. Breast. 2009;39:24-5.

2. Schein JR, Hicks RW, Nelson WW, Sikirica V, Doyle DJ. Patient-controlled analgesia-related medication errors in the postoperative period. Drug safety. 2009;32(7):549-59.

3. Hutchison RW. Challenges in acute post-operative pain management. Am J Heal Pharm. 2007;64(6):4-7.

4. West N, Nilforushan V, Stinson J, Ansermino JM, Lauder G. Critical incidents related to opioid infusions in children: A five-year review and analysis. Can J Anesth. 2014;61(4):312-21.

5. Hicks RW, Sikirica V, Nelson W, Schein JR, Cousins DD. Medication errors involving patient-controlled analgesia. Am J Heal Pharm. 2008;65(5):429-40.

6. Cohen MR, Smetzer JL. ISMP Medication Error Report Analysis-Fatal Patient-Controlled Anesthesia Adverse Events; Name Confusion with New Cancer Drugs; Medication Safety Officer Group to Become a Part of ISMP. Hosp Pharm. 2013;48(9):715-24.

7. Rich $B A$, Webster $L R$. A review of forensic implications of opioid prescribing with examples from malpractice cases involving opioid-related overdose. Pain Med. 2011;12(S2):59-66.

8. Patanwala $A E$, Keim SM, Erstad BL. Intravenous opioids for severe acute pain in the emergency department. Ann Pharmacother. 2010;44(11):1800-9.

9. Zhou Q, Fang X, Zhu L, Pan S, Xia P, Chen M. Safe medication management and use of narcotics in a Joint Commission International-accredited academic medical center hospital in the People \& amp;rsquo;s Republic of China. Ther Clin Risk Manag. 2016;12:535.

10. Cohen MR, Weber RJ, Moss J. Patient-Controlled Analgesia : Making It Safer For Patients. 2006;12. Available from http://www.ismp.org/ profdevelopment/PCAMonograph.pdf

11. Nelson KL, Yaster M, Kost-Byerly S, Monitto CL. A national survey of
American pediatric anesthesiologists: Patient-controlled analgesia and other intravenous opioid therapies in pediatric acute pain management. Anesth Analg. 2010;110(3):754-60.

12. Bravo Matus CA, Flores Zúñiga RM. Errors in Managing Postsurgical Pediatric Pain in Mexico. J Pain Palliat Care Pharmacother. 2011;25(2):1604

13. Osterbrink J, Bauer Z, Mitterlehner B, Gnass I, Kutschar P. Adherence of pain assessment to the German national standard for pain management in 12 nursing homes. Pain Res Manag. 2014;19(3):133-40.

14. Pain scales do not weigh every risk. Medication Safety Alert! Acute Care Edition. 2002. Available from: https://www.ismp.org/newsletters/acutecare/ articles/20020724.asp

15. ISMP Medication Safety Self-Assessment for Hospitals, Key Definitions. 2011;1-4. Available from: http://ismp.org/selfassessments/Hospital/2011/ definitions.pdf

16. ISMP International Medication Safety Self-Assessment $®$ for Oncology. 2012; Available from: https://www.ismp.org/selfassessments/

17. ISMP Medication Safety Self-Assessment for Antithrombotic Therapy, 2017. Available from: https://www.ismp.org/selfassessments/ Antithrombotic/2017/2017_ISMP_Antithrombotic_Self_Assessment.pdf

18. Medication Safety Self-Assessment $\AA$ for Community/Ambulatory Pharmacy. Available from: https://www.ismp-canada.org/amssa/

19. Alomi YA. National Pharmacy Pain Management Program at Ministry of Health in Saudi Arabia. J Pharmacol Clin Res. 2017;3(2).

20. Safe Use of Opioids in Hospitals. Sentinel Event Alert. 2012;49(8):1-5.

21. Mitchell JF. Oral Dosage Forms That Should Not Be Crushed. October. 2011, Available from: http://www.ismp.org/tools/donotcrush.pdf

22. Proceedings from the ISMP Summit on the Use of Smart Infusion Pumps. 2009;1-19. Available from: http://www.ismp.org/tools/guidelines/ smartpumps/printerVersion.pdf

23. ISMP Medication Safety Self-Assessment for Hospitals. Available from: http://www.ismp.org/selfassessments/hospital/2011/

24. Jungquist $C R$, Karan S, Perlis ML. Risk Factors for Opioid-Induced Excessive Respiratory Depression. Pain Manag Nurs. 2011;12(3):180-7.

25. Alomi YA. National Pharmacist Competency System at Ministry of Health Hospitals in Saudi Arabia. J Pharmacol Clin Res. 2016;1(3):1-5.

26. Alomi YA. A new Guidelines on Hospital Pharmacy Manpower in Saudi Arabia. J Pharm Pract Community Med. 2016;2(2):30-1.

27. The Joint Commission. Safe use of opioids in hospitals. Sentinel Event Alert. 2012;(49):1-5.

28. King Abdullah Bin Abdulaziz Arabic Health Encyclopedia. Available from: https://www.kaahe.org/en/

29. Alomi YA. National Medication Safety Program at Ministry of Health in Saudi Arabia. J Pharmacovigil. 2015;3:e145.

30. Alomi Y. National Pharmacy Practice Programs at Ministry of Health in Saudi Arabia. JPharm Pharm Scien. 2015;1(12):17-8.

31. Alomi YA, Kamal E. National Drug Quality Reporting System at Ministry of Health in Saudi Arabia. J Pharmacovigilance 2016, 4:3: 1000208.

Cite this article as: Alomi YA, Ibrahim EK. KSA-Self Assessment of Pain Management Medication Safety for Hospitals. J Pharm Pract Community Med. 2017;3(3):288-98. 